\title{
Dinuclear ruthenium(II) Schiff base complex: a first in vivo study in Swiss albino mice
}

\author{
Muzika $\mathrm{V}^{1 *}$, Custovic $\mathrm{S}^{1^{*}}$, Alicelebic $\mathrm{S}^{1}$, Cosovic $\mathrm{E}^{1}$, Zahirovic $\mathrm{A}^{2}$, Kahrovic $\mathrm{E}^{2}$ \\ University of Sarajevo, Faculty of Science, Department of Chemistry, Sarajevo, \\ Bosnia and Herzegovina. emira_kahrovic@yahoo.com
}

\begin{abstract}
OBJECTIVES: Dinuclear ruthenium(II) Schiff base complex was selected for in vivo study among many other novel metal-based compounds, because of its previously proved in vitro anticancer and antibacterial properties. The aim was to investigate the potential toxicity of this compound in animal model through biochemical and histopathological assessment.

METHODS: Adult Swiss albino mice of both sexes were divided into high-dose and low-dose group that received a single intraperitoneal dose of ruthenium complex (175 mg/kg and $25 \mathrm{mg} / \mathrm{kg}$, respectively) and one control group (vehicle only). After a follow-up period of 14 days, animals were sacrificed to obtain blood samples and organs. RESULTS: The test compound was well tolerated in a low-dose group and did not cause any mortality. The histological findings and serum biochemistry suggested a reversible character of alterations found in vital organs of this group. However, in the high-dose group, adverse effects were more severe and indicated dose and gender-related toxicity.

CONCLUSION: Mild side effects found in a low-dose group together with excellent in vitro properties, made dinuclear ruthenium(II) Schiff base complex a promising candidate for further investigation and development as anticancer and antimicrobial agent (Tab. 4, Fig. 6, Ref. 32). Text in PDF www.elis.sk.

KEY WORDS: ruthenium compounds, mice, toxicity tests, histology.
\end{abstract}

\section{Introduction}

The need for production of new drugs is a permanent and global challenge. The ruthenium complexes attract considerable attention over recent decades because of their unique characteristics, ranging from the chemical (ligand exchange, accessible oxidation states) to biological (transportation pathways, activation, and selectivity) $(1,2)$. Ruthenium complexes are investigated as both, potential anticancer and antimicrobial agents and a combination of those two properties is desirable in patients treated for cancer because of their increased susceptibility to infections (1, 3-6). Ruthenium complexes showed an improved selectivity and reduced side effects in comparison to platinum compounds, widely used in clinical practice $(1-4,7)$. The main target for ruthenium agents in the biological systems is still not elucidated. Even though these agents bind to DNA molecule, some authors demonstrated DNA-independent antitumor mechanisms (4, 7). Among ruthenium complexes that proved high in vitro and in vivo antitumor activ-

\footnotetext{
${ }^{1}$ University of Sarajevo, Medical Faculty, Department of Histology and Embryology, Sarajevo, Bosnia and Herzegovina, and ${ }^{2}$ University of Sarajevo, Faculty of Science, Department of Chemistry, Sarajevo, Bosnia and Herzegovina

"These authors contributed equally to this work.

Address for correspondence: E. Kahrovic, Zmaja od Bosne 33-35, 71000 Sarajevo, Bosnia and Herzegovina.

Phone: +387.33 .279910$
}

ity, NAMI-A, KP1019 and NKP1339 have entered human clinical trials $(4,7)$. These compounds showed a significant cytotoxicity, antimetastatic effects and a low general toxicity (7).

Dinuclear ruthenium(II) Schiff base complex prepared by Kahrovic et al (2) is one of the first ruthenium compounds having phenol oxygen from Schiff base as bridging ligand. In vitro studies proved that this complex has a strong anticancer activity against different cancer cell lines and is even more potent than cisplatin. Also, it exhibits antibacterial activity against Gram positive bacteria (8). Nowadays ruthenium complexes, having good anticancer and antimicrobial activities, are reported daily, but all of them are not good candidates for in vivo investigations. At least three substantial reasons candidate Ru(II) Schiff base complex of $\mathrm{N}$-(2-pyridyl)-5-chlorosalicylideneimine, over hundreds of other ruthenium(II) complexes, as promising agent for in vivo testing: (i) in vitro experiments showed that the complex binds DNA in a groove with moderate binding affinity (binding constant $3.82 \times$ $10^{4} \mathrm{M}^{-1}$ ), suggesting lower risk of genotoxicity; (ii) contrary to the classic chemotherapeutic drugs, very strong in vitro anticancer activity of this complex is not DNA dependent, implying that other biological pathways might be disrupted by the complex, which is especially important in fighting the metastases; (iii) strong antimicrobial activity of the complex, which is better or comparable to vancomycin $(2,8)$.

The evaluation of toxicity is undoubtedly one of the most important steps in the evaluation process of potential therapeutic agent. Having proven its potency in vitro and based on the facts 


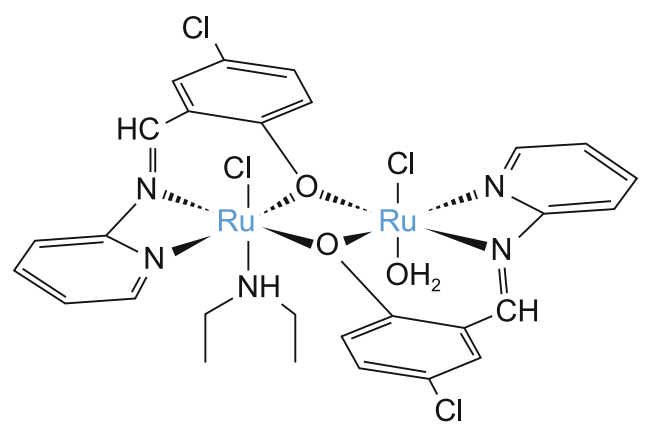

Fig. 1. Structural formula of ruthenium (II) Schiff base complex $\left[\mathrm{Ru}_{2} \mathrm{~L}_{2} \mathrm{Cl}_{2}\left(\mathrm{Et}_{2} \mathrm{NH}\right)\left(\mathrm{H}_{2} \mathrm{O}\right)\right]$.

mentioned above, the dinuclear ruthenium(II) Schiff base complex was selected for the first in vivo study to assess its safety profile.

The study was designed as a single-dose toxicity study in adult Swiss albino mice of both sexes. The aim of this study was to identify the target organs through assessment of biochemical and histopathological parameters.

\section{Materials and methods}

\section{Dinuclear ruthenium(II) Schiff base complex}

The dinuclear ruthenium(II) Schiff base complex $\left[\mathrm{Ru}_{2} \mathrm{~L}_{2} \mathrm{Cl}_{2}\left(\mathrm{Et}_{2} \mathrm{NH}\right)\left(\mathrm{H}_{2} \mathrm{O}\right)\right]$, where $\mathrm{L}$ is $\mathrm{N}$-(2-pyridyl)-5-chlorosalicylideneimine (Fig. 1) was prepared according to previously reported procedure (2). The purity of the compound was confirmed by infrared spectrum and elemental analysis.

The ruthenium(II) Schiff base complex is a dark green powder highly soluble in dimethylsulfoxide (DMSO). Fresh solutions of the complex were prepared each time prior the administration by dissolving an appropriate amount of the complex in DMSO and then diluting it with water to the required concentrations. The $\mathrm{pH}$ value of thus prepared solutions was in the range 5.20-5.50. The level of DMSO was kept below $20 \%$.

\section{Animals}

Adult (8-10 weeks old), Swiss albino mice (22.5-31.8g) of both sexes were obtained from the Faculty of Veterinary Medicine, University of Sarajevo. Only the nulliparous females were included. The mice were housed in polypropylene cages under a 12-hour light-dark cycle, temperature $23 \pm 2{ }^{\circ} \mathrm{C}$. They were fed with standard food pellets and water ad libitum. One-week acclimatization was provided before the animals were used in the experiment.

All experimental procedures were approved by the Institutional Ethics Committee and conducted in accordance with internationally accepted principles for the care and use of laboratory animals.

\section{Experimental design}

The experiment was designed as a single-dose toxicity study with a follow-up period of 14 days. The mice were randomized and divided by gender into two experimental and one control group.
The high-dose experimental group $(\mathrm{H})$ included 16 females and 16 males while low-dose experimental group (L) and the control group (C) consisted of 12 female and 12 male mice. The dose levels were selected in the light of data from the preliminary study (not published). Thus, the high dose level of $175 \mathrm{mg} / \mathrm{kg}$, represented the maximum feasible dose while a low-dose of $25 \mathrm{mg} / \mathrm{kg}$ was selected as a multiple of the probable therapeutic dose. The control group received vehicle only (DMSO). The dosing volume was $10 \mathrm{ml} / \mathrm{kg}$. Before and immediately after administration, food and water were withheld from mice.

\section{In-life observations and measurements}

After treatment, the mice were observed for signs of toxicity at intervals of $15,30,60,120,180$ minutes. Further, the animals were observed daily. The potential effects on behaviour and physiological functions were assessed using modified primary observation (Irwin) test for rodents (9). Monitoring of the experimental animals was complemented using camera with recording option (StarCam Wi-Fi IP, w/night vision; Eye4 Software). Body weight was recorded every other day.

\section{Biochemistry}

Biochemical analysis was performed on blood samples collected on sacrifice by tail snipping, to avoid compromising of cardiac tissue histological assessment. The following biochemical parameters were recorded: ALT (alanine aminotransferase), AST (aspartate aminotransferase), ALP (alkaline phosphatase), creatinine and urea using an automated chemistry analyser. All blood samples were randomly divided for detection of liver and renal functional parameters because of the relatively small amount that was obtained.

\section{Gross observation and histopathology}

At the end of the experiment, all mice were euthanized with ketamine and the necropsy was performed. Observations were made of the abdominal and thoracic cavity, as well as in situ of each organ's position, shape, colour and presence of any gross lesions. The heart, kidney, liver, spleen and ovaries/testes were carefully dissected out and weighted. Relative weight of organs

Tab. 1. Histopathology grading scale.

\begin{tabular}{clll}
\hline $\begin{array}{l}\text { Numerical } \\
\text { grade }\end{array}$ & Severity & $\begin{array}{l}\text { Morphological criteria for } \\
\text { grading }\end{array}$ & $\begin{array}{l}\text { Percentage (\%) } \\
\text { of the changed } \\
\text { tissue per slice }\end{array}$ \\
\hline 1 & Minimal & $\begin{array}{l}\text { Histological changes are } \\
\text { inconspicuous, minor and } \\
\text { infrequent }\end{array}$ & $0-10$ \\
\hline 2 & Mild & $\begin{array}{l}\text { Histological change is } \\
\text { noticeable but not a promi- } \\
\text { nent feature of the tissue }\end{array}$ & $11-20$ \\
\hline 3 & Moderate & $\begin{array}{l}\text { Histological change is } \\
\text { prominent feature of the } \\
\text { tissue }\end{array}$ & $21-40$ \\
\hline & Mistological change is the \\
& Marked & $\begin{array}{l}\text { main characteristic of the } \\
\text { tissue }\end{array}$ & $41-100$ \\
\hline
\end{tabular}


(except testes) was calculated by dividing absolute organ weight with body weight.

Representative samples of organs were than fixed in $10 \%$ buffered formalin. Paraffin-embedded tissue blocks were cut into 5 micrometres thick sections and stained with haematoxylin and eosin (HE). Histological examination of slides was made using the light microscope with digital camera (Eclipse E400, Nikon) with 40x, 100x and 400x magnification, in a blinded fashion.

Severity grading scale (Tab. 1) proposed by Shackelford et al. (10), was used for evaluation of alterations found in all harvested organs.

\section{Statistical analysis}

Statistical calculations were performed using Stat Soft Statistica 13.2. and Microsoft Excel 2016 software package. The data were expressed as the mean \pm standard deviation (SD) or median with interquartile range, depending on underlying distribution of the data. Comparisons were made using adequate parametric or nonparametric test (ANOVA and Kruskal-Wallis test, respectively) and p-value less than 0.05 was considered statistically significant.

\section{Results}

In-life observations and measurements

Clinical signs and observations

No changes of the fur, skin and mucous membranes were recorded, as well as in orifices and eyes of animals in all the groups. Summary of the clinical signs and observations is presented in the Figure 2. Lower scores for the response to stimulation were registered in the high-dose group of animals that exhibited an incomplete recovery even 48 hours after treatment. All behavioural changes were more conspicuous among males of the high-dose group.

\section{Body weight}

Until the end of experiment, all animals gained body weight even though the relative increase was twice as high in the control group $(9.81 \%)$ as it was in high-dose group (4.95 \%) (Fig. 3). When compared to the baseline, significant decrease in body weight $(-6.67 \%)$ was noted on the third day only in the highdose treated group.

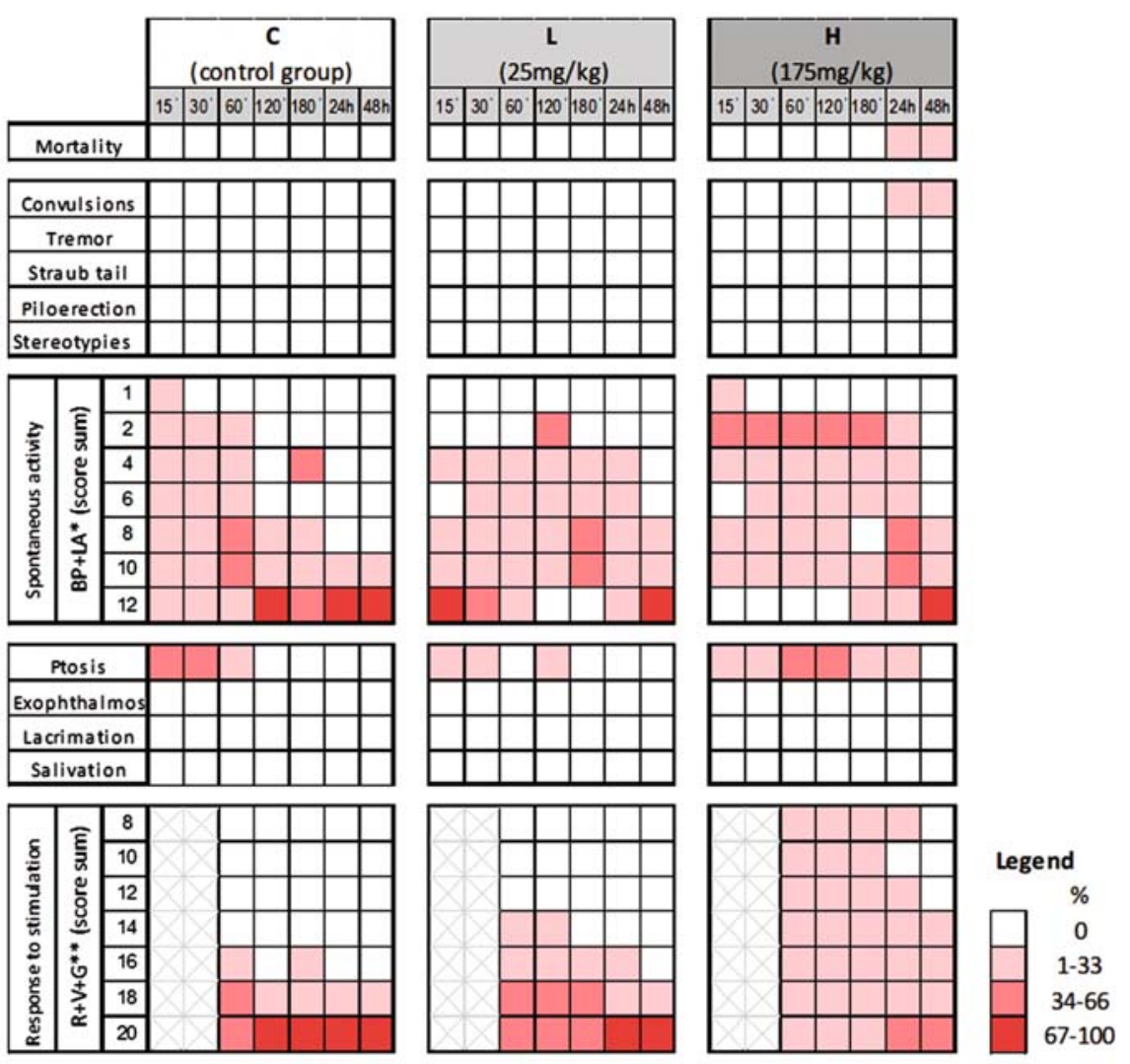

* $\mathrm{BP}=$ body position; $\mathrm{LA}=$ locomotor activity.

${ }^{* *} \mathrm{R}=$ reactivity to touch; $\mathrm{V}=$ visual placing response; $\mathrm{G}=$ grip strength.

Fig. 2. Behavioural and physiological measures of mice assessed using modified primary observation (Irwin) test. $\mathrm{C}-\operatorname{control}$ group $(\mathrm{n}=\mathbf{2 4})$, $\mathrm{L}$ - low-dose group $(\mathrm{n}=24), \mathrm{H}$ - high-dose group $(\mathrm{n}=32)$. 
Tab. 2. Mean/median value of biochemical parameters for control group (C), low-dose (L) and high-dose (H) groups of mice.

\begin{tabular}{llll}
\hline Parameter/group & C (control) & L $(25 \mathrm{mg} / \mathrm{kg})$ & $\mathrm{H}(175 \mathrm{mg} / \mathrm{kg})$ \\
\hline ALT $(\mathrm{IU} / \mathrm{L})$ & $141.50 \pm 44.88(\mathrm{n}=12)$ & $120.5(104.50-139.00)(\mathrm{n}=12)$ & $134.98 \pm 66.81(\mathrm{n}=11)$ \\
AST $(\mathrm{IU} / \mathrm{L})$ & $182.5(118.00-186.50)(\mathrm{n}=12)$ & $172.67 \pm 35.86^{* *}(\mathrm{n}=12)$ & $134.11 \pm 41.45(\mathrm{n}=11)$ \\
ALP $(\mathrm{IU} / \mathrm{L})$ & $171.92 \pm 41.83(\mathrm{n}=12)$ & $126.21 \pm 22.03^{*}(\mathrm{n}=12)$ & $161.05 \pm 45.21^{*}(\mathrm{n}=11)$ \\
Urea $(\mathrm{mg} / \mathrm{dL})$ & $7.80 \pm 2.35(\mathrm{n}=12)$ & $7.65 \pm 1.06(\mathrm{n}=12)$ & $7.12 \pm 1.08(\mathrm{n}=12)$ \\
Creatinine $(\mu \mathrm{mol} / \mathrm{L})$ & $39.49 \pm 10.65(\mathrm{n}=12)$ & $41.73 \pm 11.22(\mathrm{n}=12)$ & $41.64 \pm 9.12(\mathrm{n}=12)$ \\
\hline
\end{tabular}

The data are expressed as the mean \pm SD or median with interquartile range (IQR, 25th -75 th percentile). $*$ statistically significant result compared to control group $(\mathrm{p}<$ $0.05)$; ${ }^{* *}$ statistically significant result comparing low-dose and high-dose group $(\mathrm{p}<0.05)$.

Tab. 3. Mean relative organ weight changes ${ }^{\mathrm{a}} 14$ days after single intraperitoneal application of dinuclear ruthenium(II) Schiff base complex in mice of both sexes.

\begin{tabular}{|c|c|c|c|c|c|}
\hline \multirow{2}{*}{ Organ/Group } & & \multicolumn{2}{|c|}{ Male } & \multicolumn{2}{|c|}{ Female } \\
\hline & & Low-dose & High-dose & Low-dose & High-dose \\
\hline \multirow{2}{*}{ heart } & $\%$ change & - & -15.70 & - & - \\
\hline & incidence & - & $8 / 11$ & - & - \\
\hline \multirow{2}{*}{ kidney (left) } & $\%$ change & - & -13.10 & - & - \\
\hline & incidence & - & $10 / 11$ & - & - \\
\hline \multirow{2}{*}{ kidney (right) } & $\%$ change & -11.99 & -12.44 & - & - \\
\hline & incidence & $12 / 12$ & $11 / 11$ & - & - \\
\hline \multirow{2}{*}{ liver } & $\%$ change & - & $+17.90 * *$ & +11.44 & +15.96 \\
\hline & incidence & - & $9 / 11$ & $12 / 12$ & $16 / 16$ \\
\hline \multirow{2}{*}{ spleen } & $\%$ change & +14.09 & +42.11 & +16.52 & $+37.07 *$ \\
\hline & incidence & $5 / 12$ & $10 / 11$ & $9 / 12$ & $15 / 16$ \\
\hline \multirow{2}{*}{ testis (left) } & $\%$ change & - & +10.03 & \multirow{2}{*}{ NA } & \multirow{2}{*}{ NA } \\
\hline & incidence & - & $9 / 11$ & & \\
\hline \multirow{2}{*}{ testis (right) } & $\%$ change & - & +9.16 & \multirow{2}{*}{ NA } & \multirow{2}{*}{ NA } \\
\hline & incidence & - & $8 / 11$ & & \\
\hline \multirow{2}{*}{ ovary+bursa (left) } & $\%$ change & \multirow{2}{*}{ NA } & \multirow{2}{*}{ NA } & $-31.43 *$ & $-28.00 *$ \\
\hline & incidence & & & $10 / 12$ & $16 / 16$ \\
\hline \multirow{2}{*}{ ovary+bursa (right) } & $\%$ change & \multirow{2}{*}{ NA } & \multirow{2}{*}{ NA } & -10.28 & - \\
\hline & incidence & & & $8 / 12$ & - \\
\hline
\end{tabular}

${ }^{a}$ Mean compound treated group value compared to the mean control group value; NA - not applicable; $*$ compared to control group (p $\left.<0.05\right) ; * *$ comparing low-dose and high-dose group $(\mathrm{p}<0.05) ;$, , “ the values less than $10 \%$.

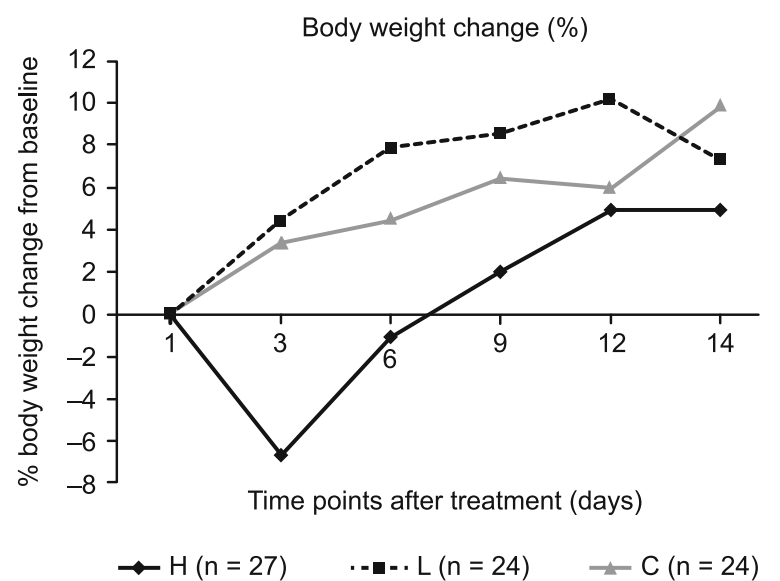

Fig. 3. Changes in body weight (\%) from initial body weight for mice in high-dose $(\mathrm{H})$, low-dose $(\mathrm{L})$ and control $(\mathrm{C})$ group, during 14-days experimental period.

\section{Mortality}

Mortality appeared only among male mice $(5 / 16 ; 31.25 \%)$ (Fig. 2). The death was preceded by a few hours of decreased activity followed by completely flattened body position. The con- vulsions appeared just a few minutes before death, according to the camera recordings.

\section{Biochemistry}

Serum biochemical parameters showed variations among the tested groups of animals as shown in Table 2. All values, except serum creatinine concentration, tended to be lower in the experimental groups. The alterations were statistically insignificant, except for ALP and AST levels.

Only in female mice of the low-dose group, ALT level (157.75 $\pm 63.37)$ and serum urea concentration $(6.98 \pm 0.89 \mathrm{mg} / \mathrm{dL})$ were significantly decreased in comparison to corresponding control group (ALT $173.50 \pm 35.18$; urea $9.40 \pm 2.36 \mathrm{mg} / \mathrm{dL}$ ).

\section{Gross observation and histopathology}

Organ weights

The mean relative organ weights from high and low-dose treated animals were compared with the mean control group values and then stratified by gender (Tab. 3). Changes of less than $10 \%$ were considered to have a small biological impact (11) and thus are not presented, except for testes. 

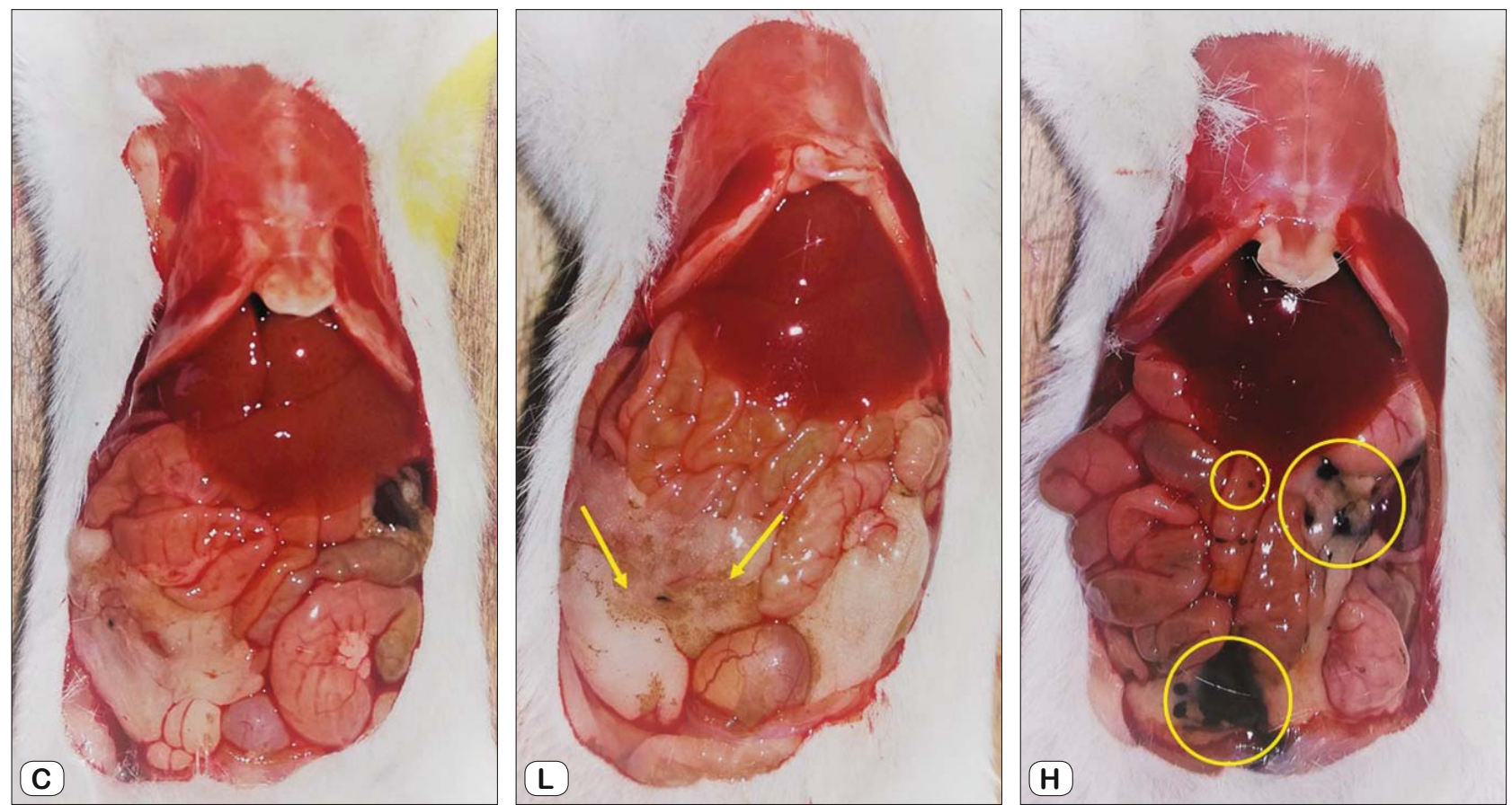

Fig. 4. Appearance of the abdominal organs on necropsy. Normal finding in the control group (C), diffuse and minute precipitate in the lowdose group (L), rough, multifocal, dark-green precipitate in the high-dose group (H).

The increase in relative liver weight was substantial among females, while the mean relative kidney weight was decreased in males of both treated groups. Spleen was enlarged in both sexes in a dose-related manner.

\section{Necropsy}

The appearance (Fig. 4) and the incidence of precipitation on peritoneal lining and adhesions among abdominal organs was different in high-dose and low-dose group of animals (Tab. 4). Thoracic cavity was devoid of precipitation, but pericardial and thymic fat appeared oedematous. The cranial mediastinal lymph nodes appeared enlarged and dark in the high-dose treated group and thus were taken out for the further histopathological evaluation.

The finding of bilaterally oedematous and soft testes was noted in all mice (11/11) in high-dose group and in only one mouse in low-dose (1/12) and the control group (1/12).

All other gross findings were incidental and routinely observed in Swiss albino mice of this age.

\section{Histopathology}

Compound-related changes were noted in multiple organs in animals of both experimental groups while the control group exhibited generally normal histological features (Fig. 5).

Myocardium of both experimental groups did not show any visible morphological alterations. Kidney and liver were affected in a dose-related manner, where the liver in females and kidneys in males seemed more altered. Changes were graded as marked in the high-dose group and minimal in low-dose group of animals.
The most prominent findings in the kidney of the high-dose group included narrowed Bowman's space with glomerular shrinkage and focal tubular hyperplasia and hypertrophy. Tubule cells exhibited basophilia accompanied with marked karyomegaly and unusual chromatin pattern ("empty nuclei"). There was no evidence of necrosis. Renal interstitial tissue was reduced.

Hepatocytes appeared enlarged and vacuolated, while their trabecular arrangement was irregular and zonation less prominent. Cytoplasmic vacuolation appeared coarser in high-dose in comparison to the low-dose group. Similarly, to the renal tubular epithelium, hepatocytes showed "empty nuclei". The nuclei of sinusoidal lining cells were prominent and hyperchromatic.

Spleen sections revealed foci of haematopoiesis that were more prominent in the high-dose group.

Testes of low-dose group revealed mostly regular seminiferous tubules and interstitium. Mildly widened interstitium and eosinophilic masses in the lumen of seminiferous tubules, along with a frequent finding of atypical residual bodies represented the features of the testis histology in the high-dose group. Ovarian follicles were mainly preserved in a low-dose group. Thickened

Tab. 4. Incidence of necropsy findings in the low-dose and high-dose group of animals.

\begin{tabular}{lcccccc}
\hline \multirow{2}{*}{ Group } & & \multicolumn{2}{c}{ precipitate } & & \multicolumn{2}{c}{ adhesions } \\
\cline { 3 - 4 } \cline { 6 - 7 } & & + & - & & + & - \\
\hline $\mathrm{L}$ & Male & $9 / 12$ & $3 / 12$ & & $0 / 12$ & $12 / 12$ \\
\cline { 2 - 4 }$(25 \mathrm{mg} / \mathrm{kg})$ & Female & $10 / 12$ & $2 / 12$ & & $2 / 12$ & $10 / 12$ \\
\hline $\mathrm{H}$ & Male & $10 / 11$ & $1 / 11$ & & $10 / 11$ & $1 / 11$ \\
\cline { 2 - 4 }$(175 \mathrm{mg} / \mathrm{kg})$ & Female & $14 / 16$ & $2 / 16$ & & $5 / 16$ & $11 / 16$ \\
\hline
\end{tabular}



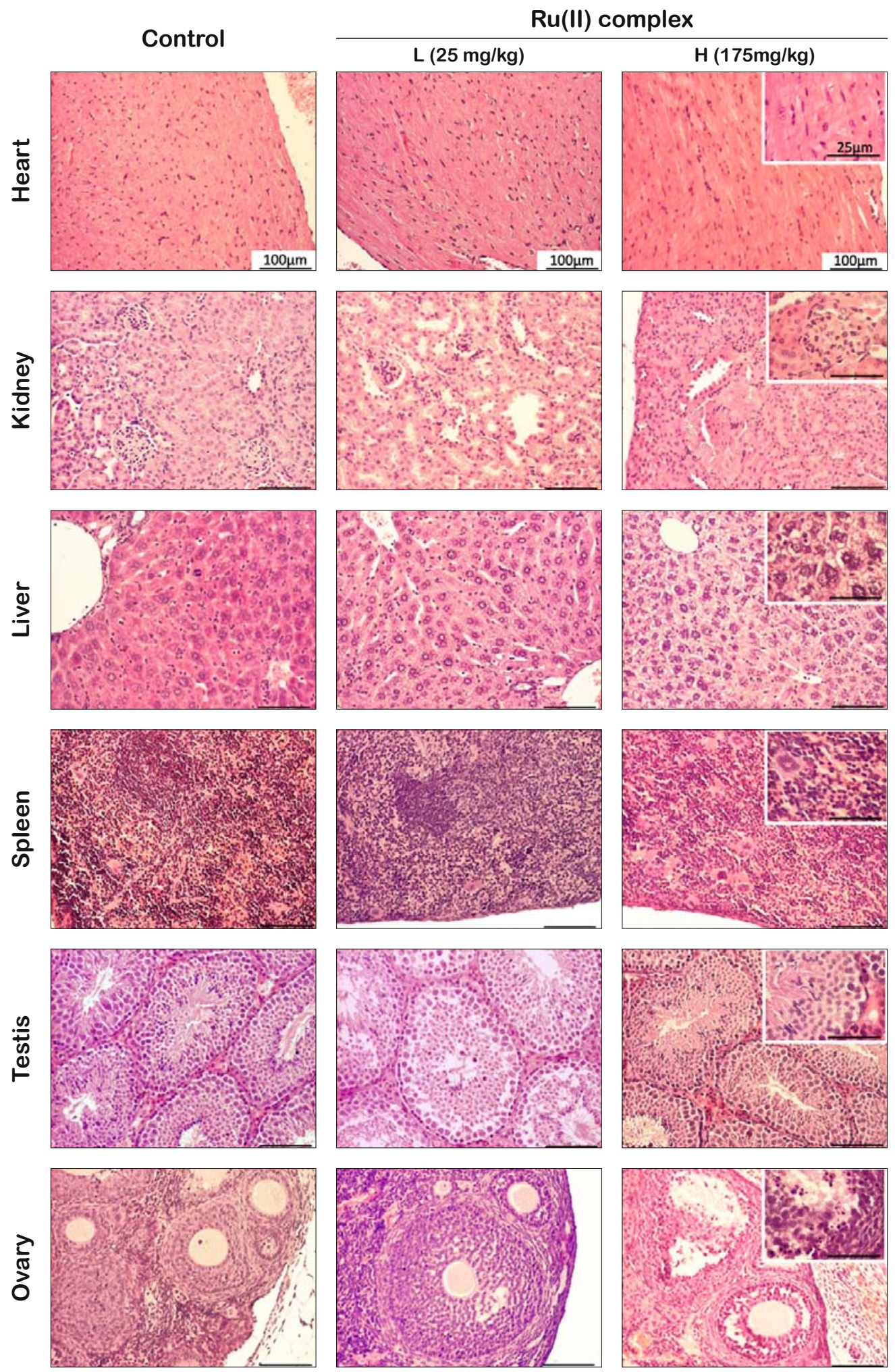

Fig. 5. Representative HE stained sections of harvested organs. Control group showing normal histology, low-dose group with minimal and high-dose group with marked structural alterations in kidney, liver, spleen and reproductive organs. 

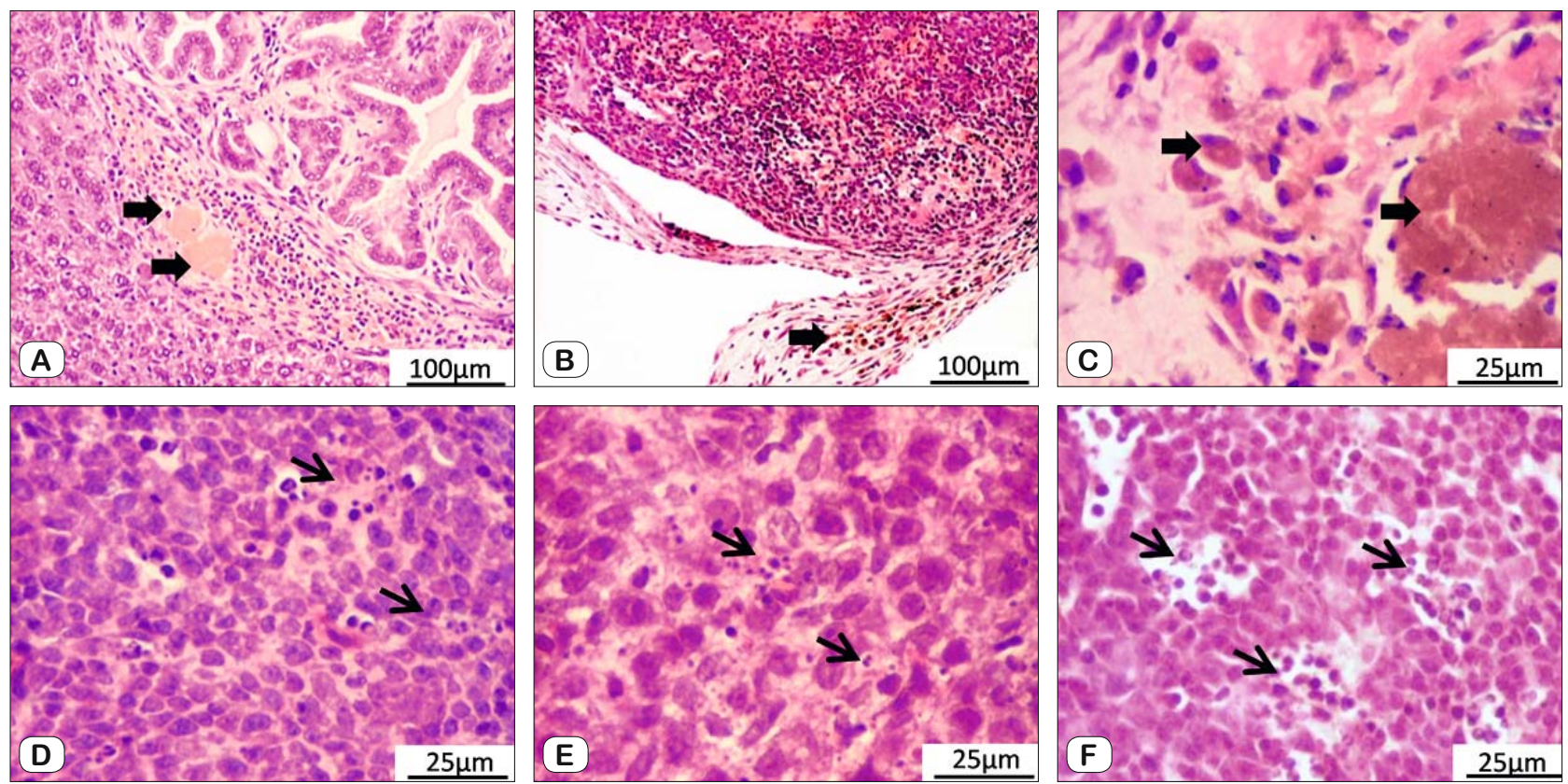

Fig. 6. Histological findings in the high-dose group of animals. The foci of yellow-brownish aggregation (thick arrow) accompanied with macrophages and other inflammatory cells in the obliterated liver interlobar fissure, near the gall bladder (A), in the thickened capsule of the spleen (B) and the wall of ovarian bursa (C). Apoptotic bodies and tangible body macrophages (arrows) in the germinative centre of the splenic lymphatic follicle (D), corpus luteum (E) and germinative centre of the cranial mediastinal lymph node (F).

bursa, hyperaemic ovarian blood vessels, rare primordial follicles and degenerating antral follicles characterised the ovaries of the high-dose treated females.

Thorough histological examination of thickened capsule (liver, spleen, ovarian bursa) revealed identical foci of macrophage aggregations with yellow-brownish cytoplasm, accompanied with other inflammatory cells (Fig. 6). Apoptotic bodies and tangible body macrophages were noted in germinative centres of the cranial mediastinal lymph nodes and white pulp of the spleen as well as in stratum granulosum of antral ovarian follicles and corpora lutea (Fig. 6).

\section{Discussion}

Among novel metal-based compounds, inspired by currently used platinum-containing drugs, ruthenium complexes appear promising. To our knowledge, this is the first in vivo study on dinuclear ruthenium(II) Schiff base complex. In previous in vitro studies, this complex showed significant anticancer and antibacterial activity $(2,8)$. Swiss albino mice of both sexes were treated with two doses of the compound to estimate the toxicity in otherwise healthy animals.

All animals of the control and low-dose group survived, while the mortality was recorded in the high-dose group, only among male mice, suggesting gender-related differences in reaction to the test substance. Generally, low-dose was well tolerated and 24 hours after treatment, the animals from this group showed the same behavioural pattern and appearance as the control group of animals, which is in accordance with the findings of other studies on acute ruthenium toxicity $(5,12)$. Lower scores on Irwin test up to 48 hours after treatment and incomplete recovery were recorded in the high-dose group, more conspicuously among males. These findings correlated with a decreased food and water intake resulting in weight gain decrease, reaching the peak on the third day. Similarly, Guichard et al (13) observed prolonged recovery and significant weight loss by third day after a single intraperitoneal administration of novel ruthenium-based compound in high-dose treated mice. This can be explained by long compound's plasma half-life, which is about 100 hours ( $\sim 3$ days) for majority of ruthenium complexes (14). Contrary to our results, Grozav et al (5) found no significant body weight changes even in the high-dose treated animals. Discrepancy can be explained with species (rat vs. mice) and gender (females vs. males) selection.

The necropsy findings of adhesive peritonitis and precipitate in abdominal cavity, confirmed by the histological analysis, were less prominent or completely absent in the low-dose group in comparison to the high-dose group. Macrophages within inflammatory infiltrate contained yellow-brownish material indicative for the presence of the test substance, while sub-mesothelial thickening with an increased cellularity was similar to those described in other types of peritonitis (15). Peritoneal adhesions and fusion of liver lobes were more frequent among male mice in the high-dose group. This is supported by the evidence, that oestrogen inhibits macrophage activation and connective tissue deposition in murine model of peritonitis (16).

Myocardium of all treated animals exhibited a preserved histological appearance. This is in accordance with the findings of other authors, who reported no or mild cardiotoxicity induced by ruthenium complexes $(17,18)$. 
The mean relative kidney weight was decreased in both experimental groups. Recorded decrease in the mean relative kidney weight in males compared to the corresponding control group was twice as high as the value found in females. The decrease in organ weight correlated with findings of reduced renal interstitial tissue and glomerular shrinkage, even though some tubules were dilated with hypertrophy and hyperplasia. Basophilia in tubular epithelium along with karyomegaly and nuclear crowding could represent a reparative response to previous injury (19). An early stage of chronic progressive nephropathy could not be excluded. Also, histological alterations of kidney were more pronounced in males. Previous studies in humans and animal models showed that the kidney is an organ with the most sex-biased gene expression resulting in higher probability of renal disease progression and higher incidence of end-stage renal disease in males (20). Similarly to Hu et al (21) and Cocchietto and Sava (22), our ruthenium complex induced renal injury limited to potentially reversible morphological changes without notable alterations in serum urea and creatinine level.

Significant increase in liver weight was detected in all treated females and only high-dose treated males. This was confirmed by histological findings of hepatocellular hypertrophy, vacuolization and capsule fibrosis. Hepatocellular hypertrophy is the main morphological feature of enzyme induction and is not necessarily followed with substantial changes in serum enzymes levels in rodents $(23,24)$. This is in accordance with results of liver enzyme assay in our study. However, lower values of liver enzymes in serum could be a sign of toxin-supressed enzyme synthesis or their altered clearance $(25,26)$. Hepatocyte cytoplasmic vacuolization, which we found in all treated animals, can be a sign of adaptive response, rather than a severe liver injury (27). Some authors $(13,18,21)$ found similar alterations in liver of animals treated with different ruthenium complexes, while Grozav et al (5) and Wang et al (4) did not report any ruthenium-induced hepatotoxicity. Our results led us to the conclusion that female mice were more susceptible to liver injury. It is known that liver-enzyme induction shows sexdifferences and drug-induced liver injury is more frequently found among females $(25,28)$.

Histological findings of increased extramedullary haematopoiesis in spleen and presence of extensive capsular fibrosis with adhesions were consisted with recorded increase in absolute and relative organ weight. Foci of apoptotic cells in germinal centres, suggesting lymphocyte depletion, were found in our study and were also reported by other authors $(5,22)$. Administration of platinum and some ruthenium complexes was associated with lymphotoxicity and myelotoxicity, while the affection of spleen represented adaptive response $(4,22,29)$.

Application of test compound caused dose-related alterations of testes and ovaries. Increased testis weight correlated with the oedematous consistency found at necropsy and interstitial oedema was observed histopathologically. When accompanied by macroscopic or microscopic findings, the change of absolute testis weight of as little as $5 \%$ is highly indicative for testicular toxicity (11). Abundant eosinophilic masses found in majority of the seminiferous tubules of high-dose treated animals, accompanied with a lack of mature sperm cells, were highly indicative for spermatids retention. Similarly to our results, the study of Ciftci et al (30) reported an increased testes weight and spermatid retention in mice treated with ruthenium complex. Spermatid retention is typically caused by reduced testosterone level that in turn is the result of interstitial oedema with short recovery period $(30,31)$.

Mean relative ovary weight was reduced in all treated females due to massive follicle atresia. Even though follicle and corpora lutea degeneration was more pronounced in high-dose group, hyperaemia and bursa fibrosis diminished ovary weight reduction detected in this group. To our knowledge, there is no data on ruthenium-induced ovarian toxicity, although chemotherapeutic agents are known for various side effects on reproductive organs, targeting oocytes or somatic cells (32).

Dinuclear ruthenium(II) Schiff base complex was well tolerated and did not cause any mortality among mice of both sexes when administered intraperitoneally in a low dose, as multiple of probable therapeutic dose. The incidence of peritoneal adhesions was negligible while histological findings and serum biochemical analysis suggested a reversible character of alterations found in vital organs of this group. However, adverse effects reported in the high-dose group were more severe, targeting different organs in male and female mice and indicating dose and gender-related toxicity. Also, irritation at the injection site caused by the maximum feasible dose, advice the future optimization of the compound's formulation.

\section{References}

1. Bergamo A, Sava G. Ruthenium complexes can target determinants of tumour malignancy. Dalton Trans 2007; (13): 1267-1272.

2. Kahrović E, Zahirović A, Turkušić E, Bektaš S. A dinuclear ruthenium(II) Schiff base complex with dissimilar coordination: synthesis, characterization, and biological activity. Z Anorg Allg Chem 2016; 642: 480-485.

3. Bergamo A, Messori L, Piccioli F, Cocchietto M, Sava G. Biological role of adduct formation of the ruthenium (III) complex NAMI-A with serum albumin and serum transferrin. Invest New Drugs 2003; 21 (4): 401-411.

4. Wang JQ, Zhang PY, Ji LN, Chao H. A ruthenium(II) complex inhibits tumor growth in vivo with fewer side-effects compared with cisplatin. J Inorg Biochem 2015; 146: 89-96.

5. Grozav A, Miclaus V, Vostinaru $O$ et al. Acute toxicity evaluation of a thiazolo arene ruthenium(II) complex in rats. Regul Toxicol Pharmacol 2016; 80: 233-240.

6. Laurent Q, Batchelor LK, Dyson PJ. Applying a Trojan horse strategy to ruthenium complexes in the pursuit of novel antibacterial agents. Organometallics 2018; 37 (6): 915-923.

7. Antonarakis ES, Emadi A. Ruthenium-based chemotherapeutics: are they ready for prime time? Cancer Chemother Pharmacol 2010; 66 (1): $1-9$.

8. Kahrović E, Zahirović A, Kraljević Pavelić S, Turkušić E, Harej A. In vitro anticancer activity of binuclear Ru (II) complexes with Schiff bases derived from 5-substituted salicylaldehyde and 2- aminopyridine with notably low IC50 values. J Coord Chem 2017; 70 (1): 1683-1697. 
9. Roux S, Sablé E, Porsolt RD. Primary observation (Irwin) test in rodents for assessing acute toxicity of a test agent and its effects on behavior and physiological function. Curr Protoc Pharmacol 2005; 27: 10.10.110.10.23.

10. Shackelford C, Long G, Wolf J, Okerberg C, Herbert R. Qualitative and quantitative analysis of nonneoplastic lesions in toxicology studies. Toxicol Pathol 2002; 30 (1): 93-96.

11. Holson JF, Nemec MD, Stump DG, Kaufman LF, Lindström P, Varsho BJ. Significance, reliability, and interpretation of developmental and reproductive toxicity study findings. In: Hood R, editor. Developmental and reproductive toxicology: a practical approach. Boca Raton: CRC Press Taylor \& Francis Group; 2006, p. 390-391.

12. Pavan FR, Poelhsitz GV, da Cunha LVP et al. In vitro and in vivo activities of ruthenium(II) phosphine/diimine/picolinate complexes (SCAR) against Mycobacterium tuberculosis. PLoS ONE 2013; 8 (5): e64242. doi: 10.1371/journal.pone. 0064242 .

13. Guichard SM, Else R, Reid E et al. Anti-tumour activity in non-small cell lung cancer models and toxicity profiles for novel ruthenium(II) based organo-metallic compounds. Biochem Pharmacol 2006; 71 (4): 408-415.

14. Lentz F, Drescher A, Lindauer A et al. Pharmacokinetics of a novel anticancer ruthenium complex (KP1019, FFC14A) in a phase I dose-escalation study. Central European Society for Anticancer Drug ResearchEWIV. Anticancer Drugs 2009; 20 (2): 97-103.

15. Margetts PJ, Kolb M, Yu L et al. Inflammatory cytokines, angiogenesis, and fibrosis in the rat peritoneum. Am J Pathol 2002; 160 (6): 2285-2294

16. Frazier-Jessen MR, Mott FJ, Witte PL, Kovacs EJ. Estrogen suppression of connective tissue deposition in a murine model of peritoneal adhesion formation. J Immunol 1996; 156 (8): 3036-3042.

17. Ciftci O, Ozdemir I, Cakir O, Demir S. The determination of oxidative damage in heart tissue of rats caused by ruthenium(II) and gold (I) Nheterocyclic carbene complexes. Toxicol Ind Health 2011; 27 (8): 735-741.

18. Yuan J, Lei Z, Wang $X$, Zhu F, Chen D. Ruthenium complex $\Lambda$-WH0402 induces hepatocellular carcinoma LM6 (HCCLM6) cell death by triggering the Beclin-1-dependent autophagy pathway. Metallomics 2015; 7 (5): 896-907.

19. Toback FG. Regeneration after acute tubular necrosis. Kidney Int 1992; 41: 226-246.
20. Si H, Banga RS, Kapitsinou Pet al. Human and murine kidneys show gender- and species-specific gene expression differences in response to injury. PLoS ONE 2009; 4 (3): e4802. doi: 10.1371/journal.pone.0004802.

21. Hu P, Wang Y, Zhang $\mathbf{Y}$ et al. Novel mononuclear ruthenium(II) complexes as potent and low-toxicity antitumour agents: synthesis, characterization, biological evaluation and mechanism of action. RSC Adv 2016; 6: 29963-29976.

22. Cocchietto M, Sava G. Blood concentration and toxicity of the antimetastasis agent NAMI-A following repeated intravenous treatment in mice. Pharmacol Toxicol 2000; 87 (5): 193-197.

23. Ennulat D, Walker D, Clemo F et al. Effects of hepatic drug-metabolizing enzyme induction on clinical pathology parameters in animals and man. Toxicol Pathol 2010; 38 (5): 810-828. doi: 10.1177/0192623310374332.

24. Maronpot RR, Yoshizawa K, Nyska A et al. Hepatic enzyme induction: histopathology. Toxicol Pathol 2010; 38 (5): 776-795.

25. Center SA. Interpretation of liver enzymes. Vet Clin North Am Small Anim Pract 2007; 37 (2): 297-333, vii.

26. Radi ZA, Koza-Taylor PH, Bell RR et al. Increased serum enzyme levels associated with Kupffer cell reduction with no signs of hepatic or skeletal muscle injury. Am J Pathol 2011; 179 (1): 240-247.

27. Nayak NC, Sathar SA, Mughal S, Duttagupta S, Mathur M, Chopra $P$. The nature and significance of liver cell vacuolation following hepatocellular injury - an analysis based on observations on rats rendered tolerant to hepatotoxic damage. Virchows Arch 1996; 428 (6): 353-365.

28. Amacher DE. Female gender as a susceptibility factor for drug-induced liver injury. Hum Exp Toxicol 2014; 33 (9): 928-939.

29. Wolfgang GHI, Dominick MA, Walsh KM, Hoeschele JD, Pegg DG. Comparative nephrotoxicity of a novel platinum compound, cisplatin, and carboplatin in male Wistar rats. Toxicological Sciences 1994; 22 (1): 73-79.

30. Ciftci O, Beytur A, Vardi N, Ozdemir I. Evaluation of reproductive toxicity in male rats treated with novel synthesized ruthenium(II) and gold (I)-NHC complexes. Drug Dev Ind Pharm 2012; 38 (1): 40-46.

31. Creasy DM. Pathogenesis of male reproductive toxicity. Toxicol Pathol 2001; 29 (1): 64-76.

32. Morgan S, Anderson RA, Gourley C, Wallace WH, Spears N. How do chemotherapeutic agents damage the ovary? Hum Reprod Update 2012; 18 (5): 525-535. 